\title{
Plastination of macroparasites: An eco-friendly method of long-term preservation
}

\author{
Niranjan Kumar ${ }^{1}$, Bhupamani Das ${ }^{1}$, Jayesh B. Solanki ${ }^{1}$, Mehul M. Jadav ${ }^{1}$ and Ramasamy Menaka²
}

1. Department of Parasitology, College of Veterinary Science and Animal Husbandry, Navsari Agricultural University, Navsari - 396 450, Gujarat, India; 2. Department of Anatomy, College of Veterinary Science and Animal Husbandry, Navsari Agricultural University, Navsari-396 450, Gujarat, India.

Corresponding author: Niranjan Kumar, e-mail: niruvet@gmail.com

Co-authors: BD: bhupa67@gmail.com, JBS: drjbsolankivet@gmail.com, MMJ: jadavvety@gmail.com, RM: menaka@nau.in

Received: 30-06-2017, Accepted: 25-10-2017, Published online: 29-11-2017

doi: 10.14202/vetworld.2017.1394-1400 How to cite this article: Kumar N, Das B, Solanki JB, Jadav MM, Menaka R (2017) Plastination of macroparasites: An eco-friendly method of long-term preservation, Veterinary World, 10(11): 1394-1400.

\begin{abstract}
Aim: Preservation of macroparasites by infiltrating the polymer in the tissues can defy the inherited shortcoming of classical wet preservation method.

Materials and Methods: Preservation was done by infiltrating the melamine alone or with xylene (MX)/chloroform (MC)/turpentine oil (MT) in 1:1 and hardener $(\mathrm{MH})$ in 9:1 ratio in the tissues of the gross specimen of the animal parasites.

Results: The plastinated models withstand the process of microbial decomposition, and remain intact in the environmental conditions. The polymer mixture resists the entry of the water molecule, and model dried just after taking out it from the water tank. Overall, the plastinated parasites were dry, non-sticky, glossy, odorless, chemical free, and harmless, to some extent flexible, with detectable morphological structure, and retain their natural form but lost their natural color. Full marks were assigned to the degree of dryness, non-stickiness, and odorlessness to the model plastinated in different solutions on a five-point scale. For flexibility, the score was 1.2, 2.2, and 2.4 for the plastinated model in melamine/MH, $\mathrm{MX} / \mathrm{MC}$, and MT solutions, respectively. The average score of glossiness was 4.6 and 5 for the specimen plastinated in melamine/MH and $\mathrm{MX} / \mathrm{MC} / \mathrm{MT}$ solutions, respectively. The degree of dryness, glossiness, stickiness, and flexibility varies non-significantly, with the polymer mixtures used.
\end{abstract}

Conclusion: The prepared model can be used to educate the students/general mass population.

Keywords: macroparasites, melamine, plastination, preservation.

\section{Introduction}

The macroparasites occupy all the ecological niche of the world and exerts ill effects on the health of the hosts (animals, birds, and human) [1,2]. There are different techniques to preserve the parasites for educational purposes in the academic institutions. The most widely accepted method of preservation is immersions and storage of the biological specimens in $10 \%$ formalin or $70 \%$ ethyl alcohol [3]. Although these materials are well-known fixative but the stored specimens are having some inherent shortcomings such as wet, with noxious odors, hazardous to the handlers, and difficult to transport. The continuously emitting noxious gas can harm the respiratory system, eyes, and skin of the handlers. Some study highlighted the role of formaldehyde as carcinogenic and neurotoxic agents [4,5]. Histological cross sections are also utilized in some teaching laboratories [6,7]. The

Copyright: Kumar, et al. Open Access. This article is distributed under the terms of the Creative Commons Attribution 4.0 International License (http://creativecommons.org/licenses/by/4.0/), which permits unrestricted use, distribution, and reproduction in any medium, provided you give appropriate credit to the original author(s) and the source, provide a link to the Creative Commons license, and indicate if changes were made. The Creative Commons Public Domain Dedication waiver (http://creativecommons.org/ publicdomain/zero/1.0/) applies to the data made available in this article, unless otherwise stated. disadvantage of histological specimens is their limitation in scope as definitive identification of the parasites requires integration with other factors [8]. The preservatives can also destroy the normal morphological features of the macroparasites, and thus, impede their identification [9-11].

Plastination technique, a method of dry preservation, is a delicate method of forced impregnation by replacing water and lipid tissues with the curable polymers, melamine or others [12-15]. Melamine is a nitrogen-rich heterocyclic triazine used primarily in the synthesis of melamine-formaldehyde resins for the manufacture of laminates, plastics, coatings, commercial filters, glues or adhesives, and molding compounds (dishware and kitchenware) [16,17]. There is a rare report of the inhalation toxicity of the melamine, but its oral exposure may cause the formation of renal calculi $[18,19]$.

The purpose of this study was to develop alternative eco-friendly method of preservation of the macroparasites describing their natural identifying features by infiltrating the melamine polymer.

\section{Materials and Methods \\ Ethical approval}

As the study was conducted utilizing the gross specimen of the animal parasites stored in $10 \%$ 
formalin in the departmental museum, so the ethical committee approval was not required.

\section{Parasites specimens}

The whole or segments of parasites belonging to Phylum: Platyhelminthes- Class Trematoda (Fasciola gigantica) and Cestoda (Moniezia spp.); Nemathelminthes- Class Nematoda (Ascaris suum, Parascaris equorum, Toxocara vitulorum, Toxocara canis, Haemonchus contortus, Oesophagostomum spp., Bunostomum spp., Trichuris ovis, and Oxyuris equi), Arthropoda- Class Insecta (Oestrus ovis and blow fly) and Arachnida (soft and hard ticks) have been plastinated.

To measure the extent of shrinkage, the dimension and weight of the plastinating materials were taken before and after impregnation of the polymer.

\section{Plastinating materials}

The melamine polymer, hardener, and touchwood of Asian Paints along with turpentine oil were procured from the local distributors. The acetone, xylene, and chloroform were of Merck make.

\section{Plastination technique}

In the present investigation, plastination technique was performed as per the method described by Menaka et al. [20] with certain modification. The selected parasites specimens were washed $24 \mathrm{~h}$ in running cold tap water $\left(5^{\circ} \mathrm{C}\right)$, to remove as much as possible formalin [21]. For dehydration, the samples were placed in 100\% acetone in the ratio 10:1 (approximately) at $-20^{\circ} \mathrm{C}$. The parasites were dehydrated in 3 changes of dehydrating agents at 1 week interval. When the dehydrating agent's concentration remained at 99\% (approximately after 3 weeks), dehydration was deemed complete [22]. The 3:1 volume ratio of polymer/polymer mixture to the macroparasites specimens was incubated at $-20^{\circ} \mathrm{C}$ for 30 days. To create an ideal plastinated model of the macroparasites, the reagents such as xylene, chloroform, turpentine oil, and hardener were added in different permutation and combination in the melamine. The polymer mixtures were prepared by mixing melamine and xylene (MX), melamine and chloroform (MC), and melamine and turpentine oil (MT) in 1:1 while melamine and hardner $(\mathrm{MH})$ in 9:1 ratio. Following the forced impregnation, the specimens were removed from the polymer/polymer mixture, and kept in a Petri dish for 2-3 days to drain the excess polymer. To impart glossy appearance, the specimens were brushed with colorless varnish.

\section{Hydrophobicity testing}

To check the power of wettability, the plastinated specimen was dipped in water for 30 minutes, and then allowed to stand at the environmental condition.

\section{Quality evaluation}

Five technical personnel were allocated to measure the extent of dryness, non-stickiness, odorlessness, glossiness, and flexibility of the prepared model on a five-point scale.

\section{Statistical analysis}

Results were compiled systematically, and data were analyzed using IBM SPSS Statistics 20.00 for Windows (SPSS Inc., Chicago, USA) to perform Chisquare tests and/or Student's t-test and/or one-way ANOVA using Duncan test (2-sided) for the determination of statistical significance. The $p>0.05$ was considered as statistically non-significant.

\section{Results}

The plastinated models withstand the process of microbial decomposition, and remain intact at environmental condition till the acceptance of the manuscript. The polymer mixture resists the entry of water molecules inside the specimens, and the model becomes dry just after taking out it from the water tank; thus, the plastinated model can be maintained even in the environment with high level of humidity.

Overall, the plastinated parasites were dry, nonsticky, glossy, odorless, chemical free, and harmless, to some extent flexible, with detectable morphological structure, and retain their natural form but lost their natural color. On a five-point scale, all five personnel assigned full marks for dryness, non-stickiness, and odorlessness to the model plastinated in different solutions. For flexibility, the score was 1.2, 2.2, and 2.4 for the plastinated model in melamine/MH, MX/MC, and MT solutions, respectively. The average score of glossiness was 4.6 and 5 for the specimen plastinated in melamine/MH and $\mathrm{MX} / \mathrm{MC} / \mathrm{MT}$ solutions, respectively. The degree of dryness, glossiness, stickiness, and flexibility of the prepared model varies non-significantly with the different polymer mixtures.

The parasites plastinated solely in melamine were dry, non-sticky, and odorless but less-glossy and brittle in nature (Figure-1).

The parasites plastinated in MX solution were dry, non-sticky, odorless, and glossy but less flexible (Figure-2a-e). The plastinated insect larvae clearly depicted the feature of immature/mature larvae of $O$. ovis, large, around $2.0 \mathrm{~cm}$ long (Table-1) with black oral hooks (Figure-2b), small rows of rose

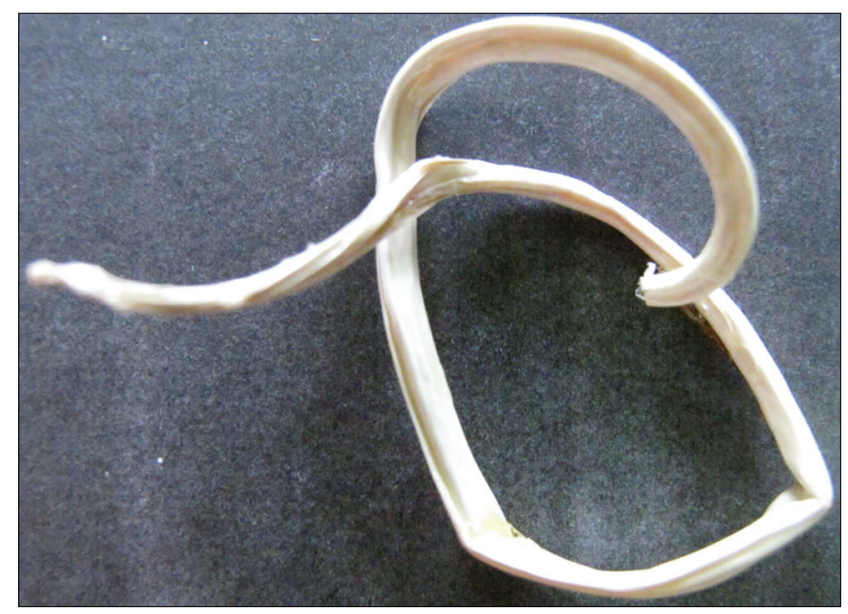

Figure-1: Parascaris equorum plastinated in melamine (M) solution. 


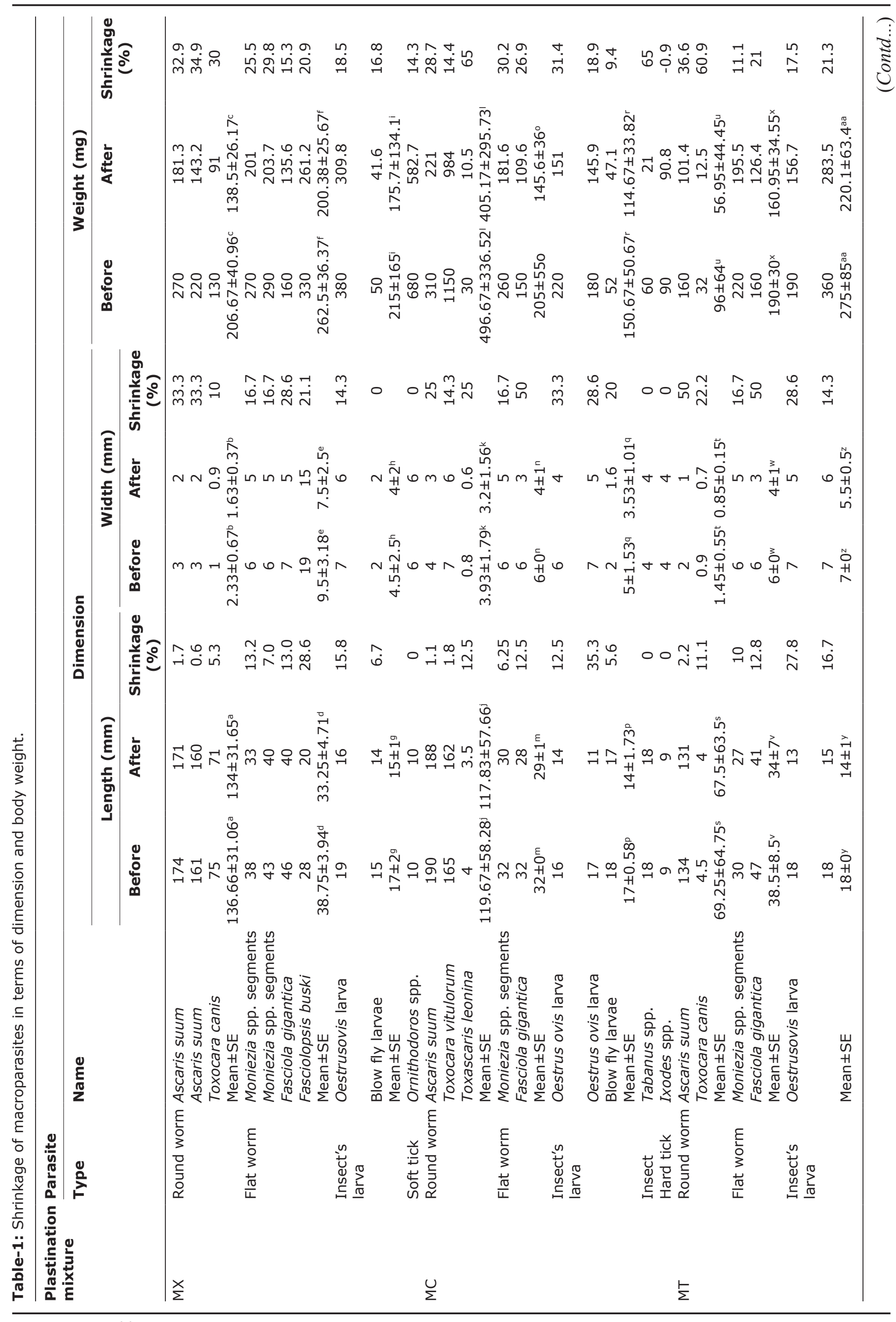




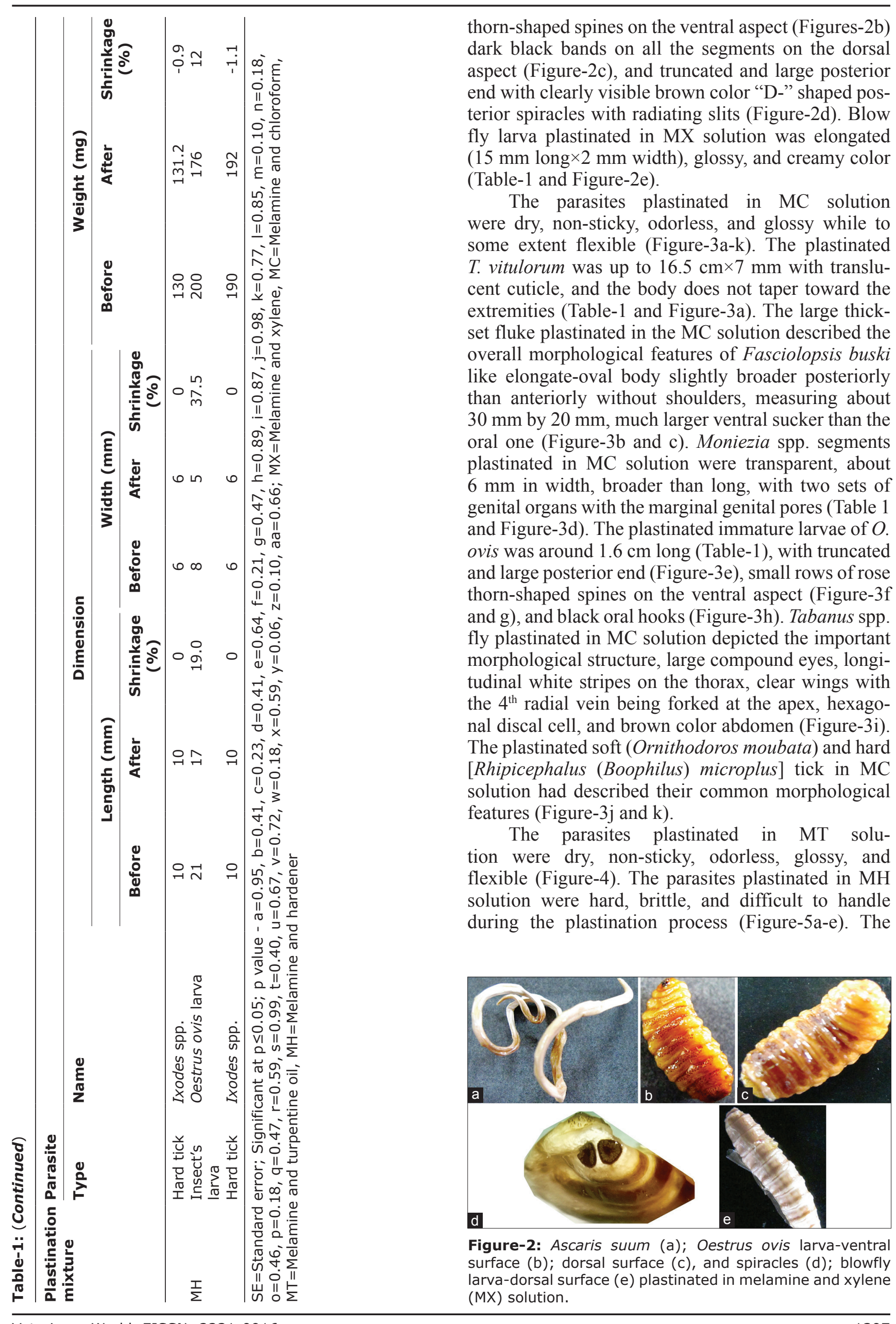




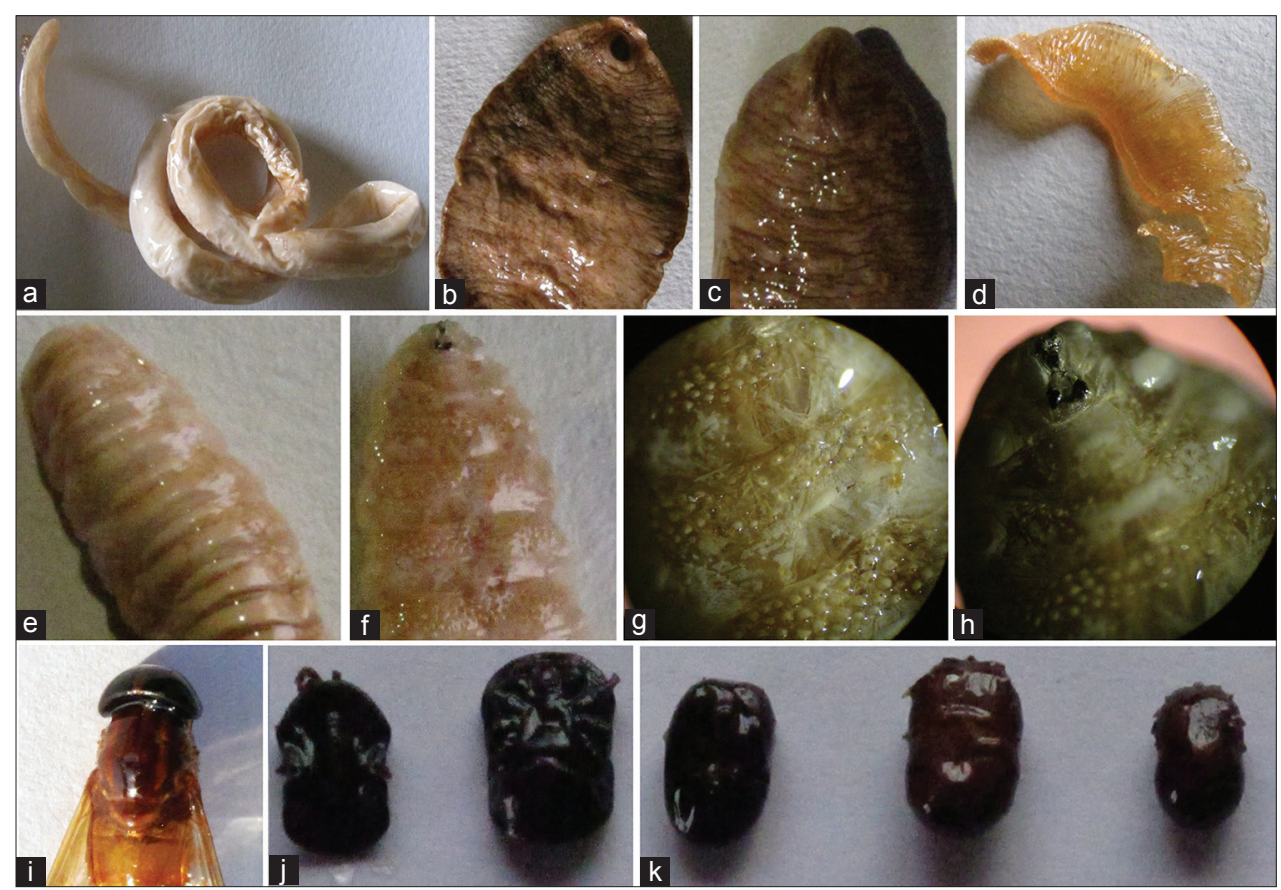

Figure-3: Toxocara vitulorum (a); Fasciolopsis buski-ventral surface (b); and dorsal surface (c); Moniezia expansa (d); immature Oestrus ovis larva-ventral surface (e); dorsal surface (f); ventral surface close view (g); and anterior end close view (h); Tabanus spp. fly (i); Ornithodoros moubata soft tick (j); Rhipicephalus (Boophilus) microplus hard tick (k) plastinated in melamine and chloroform (MC) solution.

set protocol and plastinating agent failed to yield the plastinated model of small size nematodes such as H. contortus, Oesophagostomum spp., Bunostomum spp., T. ovis, and O. equi.

Shrinkage of macroparasites in terms of dimension and body weight is summarized in Table-1. The parasites with soft body had received more shrinkage than the parasites with tough body. The tough chitinous layer (exoskeleton) of the arthropods withstands the process of shrinkage in various plastinating polymer solutions except MH. The specimens plastinated in $\mathrm{MH}$ polymer solution had received drastic overall shrinkage, and become brittle in nature (Figure-5a). Shrinkage of the round/flat worm and insect larva in terms of length, width, and weight was statistically non-significant in MX, MC, and MT plastination mixture (Table-1).

\section{Discussion}

Plastination technique was originally developed for the preservation of biological specimens in the medical world by Gunther von Hagens in 1977 [23]. The macroparasite, Ascaris lumbricoides, was first time plastinated by Asadi and Mahmodzaeh [22] through S10 Techniques. The alcohol or formaldehyde persevered parasite samples have many disadvantages such as being less permanent, having regular needs of changing the immersion solution, the unpleasant smell, and having hardly recognizable parts of the parasites [14]. Plastinated parasites can be an excellent alternative as it lowers the risk of undue exposure to the formaldehyde with higher health and safety regulations. Furthermore, the plastinated model is easy

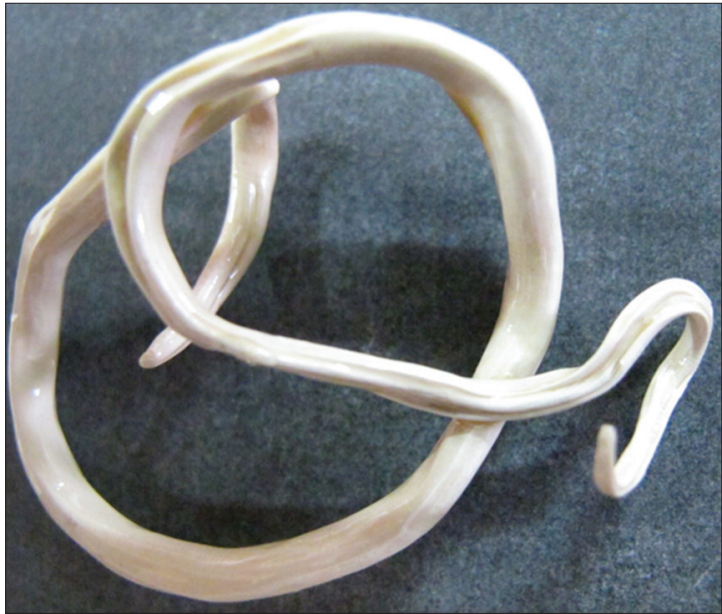

Figure-4: Ascaris suum plastinated in melamine and turpentine oil (MT) solution.

to carry, palpable, with clearly visible structure, and can be stored for an infinite period at room temperature [12].

The present study dealt with the preparation of a plastinated model of macroparasites of animal origin using melamine polymer first time in India. There is a very limited report of using melamine polymer as plastinating agents to preserve the biological specimen in native condition [20].

Laboratory grade xylene is a fair mixture of $o$, $\mathrm{p}, \mathrm{m}$, and $\mathrm{p}$ isomer and ethylbenzene (6-20\%) with the traces of toluene, trimethylbenzene, phenol, thiophene, pyridine, and hydrogen sulfide. The xylene has multivalent function, as a plasticizing agent (p-isomer is the precursor to terephthalic acid and dimethyl terephthalate, used in the production of polyethylene 


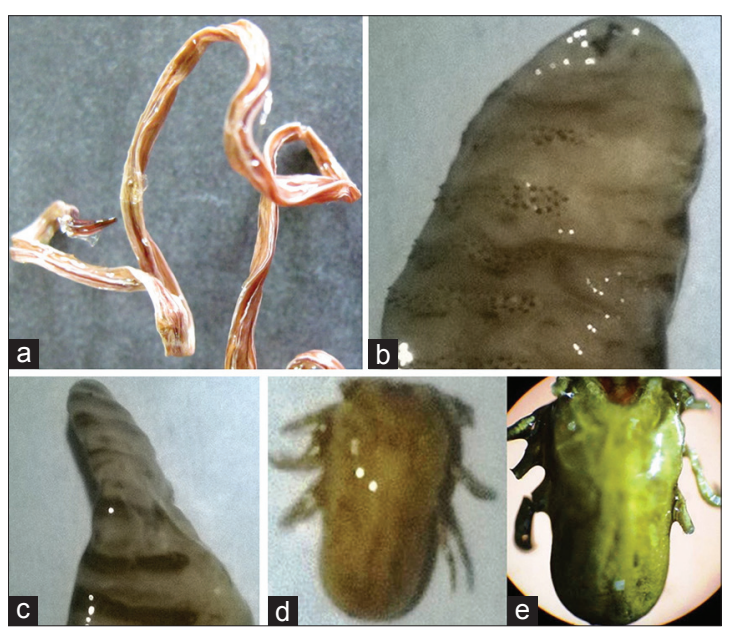

Figure-5: Ascaris suum (a); immature Oestrus ovis larvaventral surface (b) and lateral surface (c); Rhipicephalus (Boophilus) microplus ( $\mathrm{d}$ and e) plastinated in melamine and hardener $(\mathrm{MH})$ solution.

terephthalate plastic bottles and polyester clothing), mixture of $\mathrm{o}$ and $\mathrm{p}$ isomer used as a solvent (in the printing, rubber, and leather industries) for thinning paints and varnishes, as a cleaning/clearing agent (for steel, silicon wafers, integrated circuits, ear wax, and dentistry, the removal of immersion oil from objective lens/slide, and the removal of paraffin wax in the histopathology), as a cooling agent, and as an inflammable substance. Kandyala et al. [24] concluded that the high solvency of xylene/chloroform renders the tissue transparent, and enhancing the infiltration of the polymer, this feature was also noted in the specimen plastinated in the MX solution in the present investigation.

The experiment was performed under low temperature of $-20^{\circ} \mathrm{C}$ as it fixes the shape of specimens with minimum shrinkage, and further prevents its decomposition. Forced impregnation of the polymer inside the biological specimen is generally performed under vacuum/low pressure resulting in the severe shrinkage of the specimen, so the present experiment was conducted on environmental pressure to avoid this undue shrinkage, and a non-significant level of shrinkage of the round/flat worm, and insect larva in terms of length, width, and weight was noted in MX, MC, and MT plastination mixture. Sagoo and Adds [25] observed the phenomenon of shrinkage in the plastinated brain slice using Biodur TM S10/S3 polymer, and concluded $6.99 \%$ and $6.19 \%$ shrinkage in lengths and widths, respectively, was acceptable.

The plastinated specimens in the different polymer mixtures were dry and odorless, and successfully demonstrated the gross morphological features of the parasites while the color was more esthetic than that of the specimens stored in formaldehyde. The shrinkage and resulting distorted anatomy were the important observations of the present investigation, and were also observed by Miklošova and Mikloš [26] in the most ideal plastination method, silicone S10. Furthermore, Latorre et al. [27] also concluded shrinkage and color changes as the major causes of failures of the plastination technique.

The water molecule is the key player to start the process of microbial decomposition. The polymer mixtures of the present investigation critically resisted the entry of water molecules inside the specimens, thus exhibiting the antimicrobial features [28].

\section{Conclusion}

The plastinated parasitological model can be an excellent educational material for teaching the macroparasites, and technique can be used an alternative method of traditional preservation. Parasites with soft body cover require further standardization of the plastinating technique. To enhance the flexibility in the plastinated specimen, some suitable plasticizing agents should be tried in the technique.

\section{Authors' Contributions}

NK planned and accomplished the overall research work. BD and MMJ extended their physical support in performing the plastination technique. NK did the data analysis, drafted, and revised the manuscript. JBS did the initial revision of the manuscript. RM had extended the technical help in doing the plastination technique. All authors read and approved the final manuscript.

\section{Acknowledgments}

The authors are thankful to the Principal, Veterinary College, Navsari Agricultural University, Navsari, for providing necessary facilities and fund (plan budget head no. 12404) to complete the research work.

\section{Competing Interests}

The authors declare that they have no competing interests.

\section{References}

1. Thomas, F., Guegan, J.F., Michalakis, Y. and Renaud, F. (2000) Parasites and host life-history traits: Implications for community ecology and species co-existence. Int. J. Parasitol., 30: 669-674.

2. Kuris, A.M., Hechinger, R.F., Shaw, J.C., Whitney, K.L., Aguirre-Macedo, L., Boch, C.A., Dobson,A.P., Dunham, E.J., Fredensborg, B.L., Huspeni, T.C., Lorda, J., Mababa, L., Mancini, F.T., Mora, A.B., Pickering, M., Talhouk, N.L., Torchin, M.E. and Lafferty, K.D. (2008) Ecosystem energetic implications of parasite and free-living biomass in three estuaries. Nature, 454: 515-518.

3. Rosilawati, R., Baharudin, O., Syamsa, R.A., Lee, H.L. and Nazni, W.A. (2014) Effects of preservatives and killing methods on morphological features of a forensic fly, Chrysomya megacephala (Fabricius, 1794) larva. Trop. Biomed., 31(4): 785-791.

4. Hauptmann, M., Stewart, P.A., Lubin, J.H., Freeman, L.E.B., Hornung, R.W., Herrick, R.F., Hoover, R.N., Fraumeni, J.J., Blair, A. and Hayes, R.B. (2009) Mortality from lymphohematopoietic malignancies and brain cancer among embalmers exposed to formaldehyde. J. Natl. Cancer Inst., 101(24): 1696-1708.

5. Songur, A., Ozen, O.A. and Sarsilmaz, M. (2010) The toxic effects of formaldehyde on the nervous system. Rev. 
Environ. Contam. Toxicol., 203: 105-118.

6. Panyarachun, B., Ngamniyom, A., Sobhon, P. and Anuracpreeda, P. (2013) Morphology and histology of the adult Paramphistomum gracile Fischoeder, 1901. J. Vet. Sci., 14(4): 425-432.

7. Hanna, R. (2015) Fasciola hepatica: Histology of the reproductive organs and differential effects of triclabendazole on drug-sensitive and drug-resistant fluke isolates and on flukes from selected field cases. Pathogens, 4: 431-456.

8. Galant, C., Malghem, J., Sibille, C., Docquier, P.L. and Delloye, C. (2008) Current limitations to the histopathological diagnosis of some frequently encountered bone tumours. Acta. Orthop. Belg., 74: 1-6.

9. Day, D.M. and Wallma, J.F. (2008) Effect of preservative solutions on preservation of Calliphora augur and Lucilia cuprina larvae (Diptera: Calliphoridae) with implications for post-mortem interval estimates. Forensic Sci. Int., 179: $1-10$.

10. Midgley, J.M. and Villet, M.H. (2009) Effect of killing method on post-mortem change of larvae of Thanatophilus micans (Fabricus, 1794) (Coleoptera: Silphidae) stored in 70\% ethanol. Int. J. Legal Med., 123: 103-108.

11. Villet, M.H., Richards, C.S. and Midgley, J.M. (2010) Contemporary precision, bias and accuracy of minimum post-mortem interval estimated using development of carrion feeding insetcs. In: Amendt, J., Campobasso, C.P., Goff, M.L., and Grassberger, M., editors. Current Concepts in Forensic Entomology. Springer, Heidelberg. p109-137.

12. Singh, O., Mishra, B.K., Pandit, S., Maheshwari, T.P. and Hasan, S. (2013) Plastination: A promising method for preserving: A review article. Int. J. Sci. Res., 3(6): 1-3.

13. Ravikumar, C. (2014) Plastination. J. Pharm. Sci. Res., 6(8): 271-273

14. Menaka, R., Kelawala, N.H. and Vyas, K.N. (2015) Plastination technique represents a life in biological specimens-An overview. Vet. Res. Int., 3(2): 20-23.

15. Prasad, G., Karkera, B., Pandit, S., Desai, D. and Tonse, R.G. (2015) Preservation of tissue by plastination: A Review. Int. J. Adv. Health Sci., 1(11): 27-31.

16. Wu, C.F., Hsieh, T.J., Chen, B.H., Liu, C.C. and Wu, M.T (2013) A crossover study of noodle soup consumption in melamine bowls and total melamine excretion in urine. JAMA Intern. Med., 173(4): 317-319.

17. Poorjafari, N., Zamani,A., Mohseni, M. and Parizanganeh,A (2015) Assessment of residue melamine in dairy products exhibited in Zanjan market, Iran by high-performance liquid chromatography method. Int. J. Environ. Sci. Technol.,
12: 1003-1010.

18. Dobson, R.L., Motlagh, S., Quijano, M., Cambron, R.T., Baker, T.R., Pullen, A.M., Regg, B.T., Bigalow-Kern, A.S., Vennard, T., Fix, A., Reimschuessel, R., Overmann, G., Shan, Y. and Daston, G.P. (2008) Identification and characterization of toxicity of contaminants in pet food leading to an outbreak of renal toxicity in cats and dogs. Toxicol. Sci., 106(1): 251-262.

19. Reimschuessel, R., Gieseker, C.M., Miller, R.A., Ward, J., Boehmer, J., Rummel, N., Heller, D.N., Nochetto, C., de Alwis, G.K., Bataller, N., Andersen, W.C., Turnipseed, S.B., Karbiwnyk, C.M., Satzger, R.D., Crowe, J.B., Wilber, N.R., Reinhard, M.K., Roberts, J.F. and Witkowski, M.R. (2008) Evaluation of the renal effects of experimental feeding of melamine and cyanuric acid to fish and pigs. Am. J. Vet. Res., 69: 1217-1228.

20. Menaka, R., Chaurasia, S. and Kelawala, N.H. (2010) Plastination of goat (kid) cadaver-a teaching model. Indian J. Vet. Anat. 22(1): 50-51.

21. Kocevski, Z., Stefanovska, J., Ilieski, V., Pendovski, L. and Atanaskova, E. (2010) Improved determination of macroscopic parasite preparations using S10 modified plastination procedure. Mac. Vet. Rev., 33(2): 7-14.

22. Asadi, M.H. and Mahmodzaeh, A. (2004) Ascaris plastination through S10 techniques. J. Int. Soc. Plastination, 19: $20-21$.

23. von Hagens, G.,Tiedmann, K. and Kriz, W. (1987) The current potential of plastination. Anat. Embryol. (Berlin), 175(4): 411-421.

24. Kandyala, R., Phani, S., Raghavendra, C. and Rajasekharan, S.T. (2010) Xylene: An overview of its health hazards and preventive measures. J. Oral. Maxillofac. Pathol., 14(1): 1-5.

25. Sagoo, M.G. and Adds, P.J. (2013) Low-temperature dehydration and room-temperature impregnation of brain slices using Biodur TM S10/S3. J. Plastination, 25(1): 3-8.

26. Miklošova, M. and Mikloš, V. (2004) Plastination with silicone method S10- monitoring and analysis causes of failure. Biomed. Pap., 148(2): 237-238.

27. Latorre, R.M., Reed, R.B., Gil, F., Azla, M.D., MartinezGomariz, F. and Henry, R.W. (2002) Epoxy impregnation without hardener: To decrease yellowing, to delay casting, and to aid bubble removal. J. Int. Soc. Plastination, 17: 17-22.

28. Rahangdale, S.S. (2012) Synthesis, characterization and antimicrobial activity of resorcinol-melamine-formaldehyde resin. J. Chem. Pharm. Res., 4(10): 4451-4458. 